\title{
Cell shape and plasma membrane alterations after static magnetic fields exposure
}

\author{
A. Chionna, M. Dwikat, E. Panzarini, B. Tenuzzo, E.C. Carlà, T. Verri, P. Pagliara, L. Abbro, L. Dini \\ Dept. of Biological and Environmental Science and Technology, University of Lecce, Italy
}

.

(C)2003, European Journal of Histochemistry

The biological effects of static magnetic fields (MFs) with intensity of $6 \mathrm{mT}$ were investigated in lymphocytes and U937 cells in the presence or absence of apoptosis-inducing drugs by transmission (TEM) and scanning (SEM) electron microscopy. Lectin cytochemistry of ConA-FITC conjugates was used to analyze plasma membrane structural modifications. Static MFs modified cell shape, plasma membrane and increased the level of intracellular $\left[\mathrm{Ca}^{++}\right.$which plays an antiapoptotic role in both cell types. Modifications induced by the exposure to static MFs were irrespective of the presence or absence of apoptotic drugs or the cell type. Abundant lamellar-shaped microvilli were observed upon 24 hrs of continuous exposure to static MFs in contrast to the normally rough surface of U937 cells having numerous short microvilli. Conversely, lymphocytes lost their round shape and became irregularly elongated; lamellar shaped microvilli were found when cells were simultaneosly exposed to static MFs and apoptosis-inducing drugs. In our experiments, static MFs reduced the smoothness of the cell surface and partially impeded changes in distribution of cell surface glycans, both features being typical of apoptotic cells. Cell shape and plasma membrane structure modifications upon static MFs exposure were time-dependent. Lamellar microvilli were clearly observed before the distortion of cell shape, which was found at long times of exposure. MFs exposure promoted the rearrangement of F-actin filaments which, in turn, could be responsible for the cell surface modifications. Here we report data that support biological effects of static MFs on U937 cells and human lymphocytes. However, the involvement of these modifications in the onset of diseases needs to be further elucidated.

Key words: Static MFs, apoptosis, lymphocytes, U937cells, cell surface, cytoskeleton

Correspondence: Prof. Luciana Dini, Dept. of Biological and Environmental Science and Technology, University of Lecce, via per Monteroni, 73100 Lecce, Italy. Phone: international +39.0832.298614. Fax international +39.0832.298626.

E-mail: Iuciana.dini@unile.it

Paper accepted on April 17, 2003

European Journal of Histochemistry

2003; vol. 47 issue 4 [0ct-Dec]:299-308
A growing interest in the influence of magnetic fields (MFs) on life processes is deriving from concerns about their possible harmful effects on human health. More and more evidence has been gathered during the last years about the hazardous consequences of the so-called electromagnetic pollution. Although the data reported in the literature are quite heterogeneous with regards to MF intensity (from $10^{-7}$ to $10 \mathrm{~T}$ ), type of fields (static or oscillatory), and subjects exposed to MFs (from in vitro cultured cells to humans), a link between MFs and tumor genesis has been suggested (McCann et al. 1993). However, a direct tumor genesis or mutagenesis has never been attributed to MFs (Morandi et al. 1996). Differences in exposure systems and conditions complicate the evaluation of studies indicating biological effects of MFs. MFs are claimed to stimulate multiple responses in the cells: i) interfere with the proliferation capability of mammalian cells in vitro (Ross 1990); ii) enhance the mutation rates of cells exposed to various mutagenic compounds (Nordenson et al. 1994; Miyakoshi et al. 1996); iii) increase the survival of tumor cells after cytocidal therapies (Liburdy et al. 19939); iv) increase the tumor rate in cancer-susceptible mouse strains (Morandi et al. 1996); v) influence neoplastic development through alterations in the expression of cancer related genes (Loberg et al. 2000). Other studies indicate effects of MFs on the different functions of subcellular organelles; MFs induce i) lipid peroxidation and generation of reactive oxygen species (Ishisaka et.al. 2000); ii) DNA damage (Fiorani et al. 1992); iii) intracellular calcium signaling (Lyle et al. 1997). A possible interference of static MFs with the apoptotic process has been reported as well, showing an increase of cell survival by both inhibiting apoptosis via modulation of capacitative $\mathrm{Ca}^{2+}$ influx (Fanelli et al. 1999), and altering the expression of apoptosis-related genes (bcl2, p53) (manuscript in preparation). Alterations in intracellular signaling, such as potentiation of the effect of phor- 
bol-12-myristate 13-acetate (PMA) on $\mathrm{O}_{2}$ generation and $\beta$-glucuronidase release in polymorphonuclear leukocytes, have also been described (Khadir et al. 1999).

Most of the theories addressing the mechanism of interaction between biological systems and MFs suggest that the primary site of interaction is the plasma membrane, whose structural and biophysical changes affect receptor binding or activation, and thereby affect cell function in general (Paradisi et al. 1993). The effects described for membrane responses to MFs are consistent with the demonstrated reorientation of diamagnetic molecular domains within the membrane (Rosen 1993).

A more precise knowledge of the plasma membrane and/or cell surface perturbation exerted by static MFs exposure could help to gain insight into the biological role of magnetic fields which, in turn, could have the same therapeutic advantages shown for electromagnetic fields in the healing of bone fractures or, in the opposite way, in metastatic cell detachment in cancer (Goodman et al. 1995; Blank 1995; Johnson et al. 2001). Moreover, it is general knowledge that morphological changes, mainly limited to the plasma membrane, are linked to functional alterations, i.e. phagocytosis. Therefore, in the present study, an investigation of the ultrastuctural changes (cell shape, plasma membrane and cytoskeletal changes) induced by the exposure to static MFs, in isolated peripheral lymphocytes and in the monocytic cell line U937, in the presence and absence of apoptotic-inducing drugs, was performed.

\section{Materials and Methods}

\section{Cells and treatments}

\section{Cells and cultures}

The pro monocytic U937 cells were cultured in RPMI 1640 medium supplemented with $10 \%$ inactivated fetal calf serum, 2 mM L-glutamine, 10,000 $\mathrm{IU} / \mathrm{mL}$ nistatine, $100 \mathrm{IU} / \mathrm{mL}$ penicillin and streptomycin in a humidified atmosphere of $5 \% \mathrm{CO}_{2}$; cells were used at the density of $5 \times 10^{5}$.

Peripheral blood mononuclear cells were obtained after Ficoll gradient separation of buffy coats from blood donations of non-smoking healthy males, aged 25 to 45. Peripheral blood lymphocytes were separated from monocytes by double adherence to plastic; they were over $95 \%$ pure as evaluated by morphological criteria. During and after the treatment they were maintained at a cell density of $1 \times 10^{6}$ cells $/ \mathrm{mL}$, in complete culture medium at $37^{\circ} \mathrm{C}$, supplemented with $10 \%$ inactivated fetal calf serum, 2 $\mathrm{mM}$ L-glutamine, $100 \mathrm{IU} / \mathrm{mL}$ penicillin and streptomycin in a humidified atmosphere of $5 \% \mathrm{CO}_{2}$; cells were used on the first day of explant.

\section{Induction of apoptosis}

Apoptosis was induced with $10^{-2} \mathrm{M}$ cycloheximide ( $\mathrm{CHX)} \mathrm{for} \mathrm{up} \mathrm{to} 18 \mathrm{hrs}$ or $24 \mathrm{hrs}$, followed by a $1 \mathrm{hr}$ recovery period in fresh medium; $1 \mathrm{mM} \mathrm{H}_{2} \mathrm{O}_{2}$ for 1 $\mathrm{hr}$, followed by a $1 \mathrm{hr}$ recovery period; $1 \mathrm{\mu g} / \mathrm{mL}$ puromycin (PMC) for up to 6 hours.

\section{Magnetic field application}

Static MFs were applied as reported by Fanelli et al. (1999). Briefly, static MFs were produced by metal magnetic disks of known intensities; magnets produce static without producing alternating MFs. Unlike electric field-driven, solenoid-generated MFs, static MFs do not induce any temperature increase. Static MFs intensity is given in millitesla ( 1 $\left.\mathrm{T}=10^{4} \mathrm{G}\right)$. The intensity $(6 \mathrm{mT})$ chosen according to Fanelli et al. (1999), corresponds to the antiapoptotic plateau.

Magnets were placed under the plastic culture Petri dishes. Since static MFs intensity decreases according to the square of the distance, the actual field intensity on the cells was calculated considering the thickness of the bottom of the Petri dish ( 1.2 $\mathrm{mm}$ ). Static MFs were applied concomitantly with the apoptogenic treatments, unless otherwise specified.

\section{Recovery}

After apoptogenic treatment in the presence or absence of 6 mT static MFs, drugs were washed out and lymphocytes and U937 cells were seeded in quadruplicate at the same density $(1 \times 106 \mathrm{cells} / \mathrm{mL})$. For each treatment, two Petri dishes were placed outside, and two inside, the $6 \mathrm{mT}$ static MFs. At the times indicated, apoptosis was quantitated and the number of viable cells was estimated in a hemocytomer.

\section{Analysis of apoptosis}

Cell viability was assessed by membrane impermeability to trypan blue and propidium iodide, positive staining with vital dyes, normal nuclear shape and texture revealed upon vital staining with Hoechst 33342, hematoxylin and eosin staining (Bonanno et al. 2002). Apoptosis was detected by light 
microscopy and by cytofluorimetry. Nuclear fragmentation was detected after staining with Hoechst $33342(1 \mu \mathrm{g} / \mathrm{mL})$ according to nuclear morphological features (Bonanno et al. 2002).

\section{Quantitation of apoptosis}

The percentage of apoptotic and viable cell fractions was performed by cytometry with an EPICS XL cytofluorimeter (Coulter Electronic Inc., Hialeah, $\mathrm{FL}, \mathrm{USA}$ ) equipped with a $5-\mathrm{W}$ argon laser having a 488-nm excitation wavelength. The fixed cells were stained with propidium iodide $(10 \mu \mathrm{g} / \mathrm{mL})$ in phosphate buffered saline containing 40 units $/ \mathrm{mL}$ RNase and $0.5 \%$ Tween 20 . The $635-\mathrm{nm}$ emission wavelength was monitored for propidium iodide emission. The apoptotic fraction was calculated by evaluation of the subGI DNA. For each flow cytometric analysis, at least 10,000 events were calculated.

\section{Trasmission and scanning electron microscopy}

Ultrastructure of lymphocytes and U937 cells was obtained by trasmission (TEM) and scanning (SEM) electron microscopy. A quantity of $10^{6}$ cells $/ \mathrm{mL}$ were fixed with $2.5 \%$ glutaraldehyde in cacodylate buffer, $\mathrm{pH} 7.4$, for $\mathrm{Ih}$ at ice temperature and postfixed with $1 \% \mathrm{OsO}_{4}$ in the same buffer; afterwards, samples were dehydrated, embedded in Spurr resin and examined under a Philips $\mathrm{CM}_{12}$ TEM. SEM observations were performed on cells deposited on APES (2\% in acetone)-treated coverslip slides. A Critical Point Dryer 020 Balzer and a Sputter Coated 040 Balzer were used for the final preparation steps. Cells were examined under a Philips XL50 scanning microscope.

\section{Lectins and phalloidin cytochemistry}

U937 cells, fixed with 4\% paraformaldehyde in phosphate buffer, $\mathrm{pH} 7.4$, for $10 \mathrm{~min}$ and deposited on gelatin-treated microscopy slides, were analyzed for surface localization of sugars by using Concanavalin-A (Con-A) $(40 \mu \mathrm{g} / \mathrm{mL}$ mannose) and Ricinus communnis ( $2 \mu \mathrm{g} / \mathrm{mL}$ D-galactose) FITC conjugates for $30 \mathrm{~min}$ in the dark. Phalloidin-FITC conjugate was used at a concentration of $20 \mu \mathrm{M}$ for $20 \mathrm{~min}$. Samples were observed by using a Nikon PCM 2000 microscope (Nikon, Japan) with Plan Fluor objectives (Nikon). Confocal microscopy was performed using a confocal laser scanning head Nikon PCM 2000 based on a Nikon Eclipse 600 microscope. Acquisition and visualization are completely computer-controlled through EZ 2000 software (Coord-
Nikon, The Netherlands) (Diaspro, 2002).

Samples labelled with FITC-conjugate lectins were excited with an Argon Laser ED HeNe $488 \mathrm{~nm}$, equipped with $543 \mathrm{~nm}$ emission source.

\section{Measurements of $\mathrm{Ca}^{2+}$ levels}

Cells $\left(5 \times 10^{7}\right.$ cells at a concentration of $\left.1 \times 10^{6} / \mathrm{mL}\right)$ were washed twice with loading buffer (120 mM $\mathrm{NaCl}, 5.4 \mathrm{mM} \mathrm{KCl}, 4.2 \mathrm{mM} \mathrm{NaHCO}_{3}, 1.2 \mathrm{mM}$ $\mathrm{KH}_{2} \mathrm{PO}_{4}, 1.3 \mathrm{mM} \mathrm{CaCl}, 1.3 \mathrm{mM} \mathrm{MgSO}_{4}, 20 \mathrm{mM}$ Hepes, $15 \mathrm{mM}$ glucose, 2\% BSA equilibrated with $\left.\mathrm{CO}_{2}\right)$, re-suspended at a final concentration of $2 \times 10^{7}$ cells $/ \mathrm{mL}$ and then loaded with $4 \mu \mathrm{M}$ fura- 2 acetoxymethylesther (AM) for 30 min at room temperature. After dye loading procedure, cells were washed twice with the same loading buffer and then re-suspended in fresh loading buffer at the final concentration of $3 \times 10^{6}$ cells $/ \mathrm{mL}$. Cells were stored at room temperature until use and pre-warmed at $37^{\circ} \mathrm{C}$ for 2 min before measurements. The fluorescence of fura-2 was measured using a Jasco FP-750 spectrofluorometer, equipped with an electronic stirring system and a thermostabilized $\left(37^{\circ} \mathrm{C}\right)$ cuvette holder and controlled by a personal computer running the Jasco Spectra Manager software for Windows 95 (Jasco Europe s.r.l., Lecco, Italy). Excitation wavelengths were $340 \mathrm{~nm}$ and $380 \mathrm{~nm}$ and emission wavelength $510 \mathrm{~nm}$, respectively and slit widths were set to $10 \mathrm{~nm}$. In a glass cuvette, $2 \mathrm{~mL}$ of cell suspension, at the final concentration of $3 \times 10^{6}$ cells $/ \mathrm{mL}$, were added. Fluorescence values were converted to $\left[\mathrm{Ca}^{2+}\right]$ values according to Grynkiewicz et al. (1995).

\section{Results}

\section{Viability, apoptotic rate and $\mathrm{Ca}^{2+}$ concentration}

In the present work, static MFs at an intensity of $6 \mathrm{mT}$ were used and applied for up to five days to freshly isolated human lymphocytes and to U937 cells. This usage did not exert toxic or apoptotic effects and only slightly interfered with the normal rate of cell growth (plus 10\% of mitosis in U937 cells). However, static MFs exposure of cells resulted in an altered apoptotic rate when the cells were incubated with apoptotic drugs during the exposure. In particular, in our experimental model, an inhibitory effect on apoptosis by static MFs was measured in both lymphocytes and U937 cells. The apoptotic rate of U937 cells was reduced by 20-30\% when incubated with $\mathrm{PMC}, \mathrm{CHX}$ or $\mathrm{H}_{2} \mathrm{O}_{2}$ in the presence 

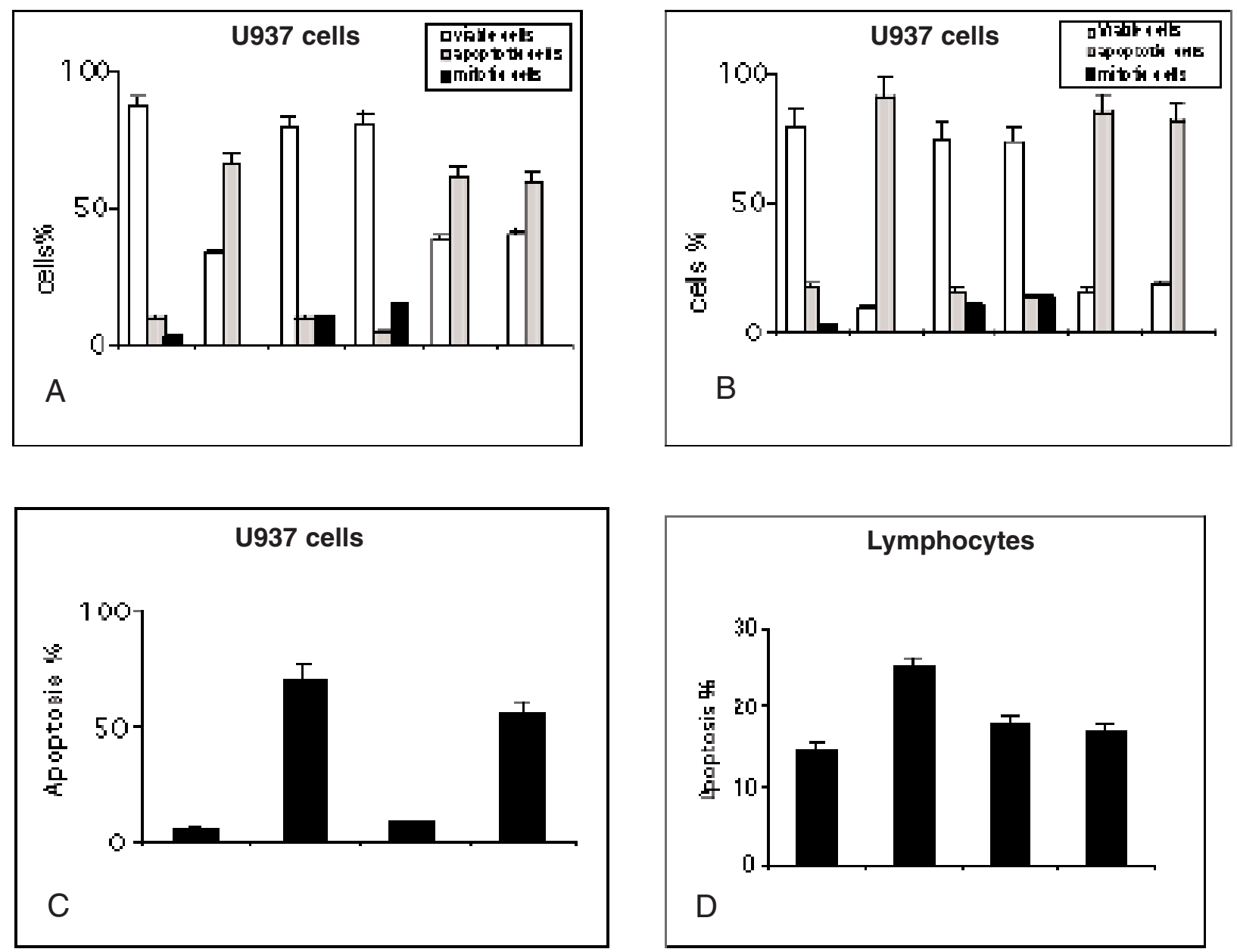

Figure 1. Cytofluorimetric evaluation of the viability, as well as the apoptotic and mitotic rates of U937 cells (a-c) and lymphocytes (d) in the presence and absence of apoptosis inducing drugs and static MFs of $6 \mathrm{mT}$ intensity. $6 \mathrm{mT}$ magnetic fields reduce H202, CHX or PMC-induced apoptosis. Values are average values \pm SD of five (U937 cells) or three (lymphocytes) independently performed experiments, each in duplicate. $\mathrm{PMC}=$ puromycin $(1 \mathrm{\mu g} / \mathrm{mL}) ; \mathrm{CHX}=$ cycloheximide $\left(10^{-2} \mathrm{M}\right) ; \mathrm{H}_{2} \mathrm{O}_{2}=$ hydrogen peroxide $(1 \mu \mathrm{M})$.

of static MFs (Figure $1 \mathrm{a}, \mathrm{b}, \mathrm{c}$ ) and by $10-15 \%$ in lymphocytes treated with $\mathrm{CHX}$ or $\mathrm{H}_{2} \mathrm{O}_{2}$. The rate of apoptosis was affected by static MFs independently of the inducers used, thus showing that MFs reduced apoptosis by interfering with the apoptotic process and not with the inducers.

Since a reduction in the apoptotic rate has already been reported upon static MFs exposure of U937 cells and lymphocytes, due to modulation of $\mathrm{Ca}^{2+}$ influx (Fanelli et al.1999), the static MFs effects on intracellular levels of $\mathrm{Ca}^{2+}$ in control and apoptosing U937 cells and lymphocytes was monitored in parallel. Data reported in Figure 2 show the intracellular increase of $\mathrm{Ca}^{2+}$ measured upon static MFs exposure. The exposure to static MFs significantly modified the $\mathrm{Ca}^{2+}$ levels in both cell types.

\section{Lymphocytes}

Normal lymphocytes are characterized by a regular round cellular shape with microvilli randomly distributed all over the cell surface (Figure $3 \mathrm{a}$ ). When lymphocytes were treated with $1 \mathrm{mM} \mathrm{H} \mathrm{H}_{2}$ for $1 \mathrm{hr}$ or $10^{-2} \mathrm{M} \mathrm{CHX}$ for $18 \mathrm{hrs}$, the rate of apoptosis in the culture increased up to about $22 \%$ and $28 \%$, respectively (Figure $1 d$ ). SEM investigation of apoptotic cells showed rounded lymphocytes with smooth surfaces due to the loss of microvilli (Figure $3 \mathrm{c}$ ). When lymphocytes, incubated with apoptogenic drugs, were concomitantly exposed to static MFs a marked alteration of their cellular shape was observed. In particular, application of static MFs to lymphocytes treated with $\mathrm{CHX}\left(10^{-2} \mathrm{M}\right.$ for 18hrs) caused structural modifications of membrane 

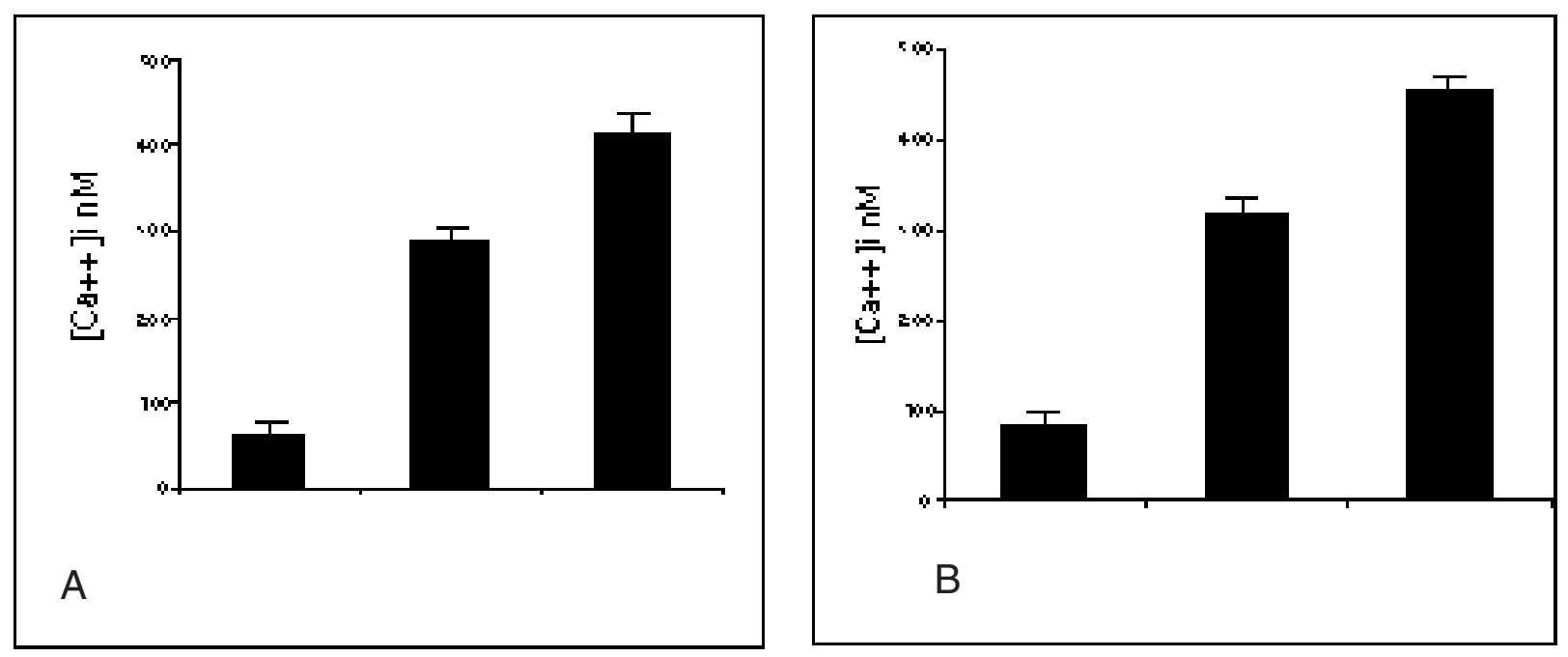

Figure 2. Evaluation of concentration of calcium ions by fura-2 (see Materials and Methods) in U937 cells (a) and lymphocytes (b) treated with PMC $(1 \mu \mathrm{g} / \mathrm{mL})$ or $\mathrm{CHX}\left(10^{-2} \mathrm{M}\right)$, respectively, in the presence of static MFs of $6 \mathrm{mT}$ of intensity. Magnetic fields increase the concentration of calcium ions of three and two folds, respectively, both in apoptotic U937 cells and lymphocytes.

microvilli, which became lamellar (Figure 3d). In addition, the lymphocytes lost they round shape and became irregularly elongated (Figure 3b). When cells were exposed to static MFs only, a slight reshaping of the cell surface was monitored. In fact, the modifications were less pronounced than in apoptotic drug-treated cells (Figure $3 d$ ). The possible effects of prolonged exposure to static MFs on the cellular shape of lymphocytes has not yet been investigated.

Cell surface modifications accompanied both apoptosis and static MFs exposure (Figure 3e-h). In fact, Con-A-FITC binding was altered by the apoptotic treatment (Figure $3 f$ ) as well as by the static MFs exposure (Figure 3g-h). During apoptosis, the exposure of sugar residues increased and their distribution was changed. Following exposure to static MFs, in control human lymphocytes the Con-A-FITC binding pattern was modified, and fluorescence concentrated on the cell periphery with a crescent shape. The modifications exerted by the apoptotic treatment were prevented by static MFs exposure: the labeling was similar to those observed for untreated lymphocytes.

\section{U937 cells}

Static MFs applied on U937 cells mostly led to cell surface modifications. In fact, abundant lamellar-shaped microvilli were observed upon $24 \mathrm{hrs}$ of continuous exposure to static MFs (Figure 4 b, b'), in contrast to the normal rough surface of the cells with many, short microvilli (Figure $4 \mathrm{a}, \mathrm{a}^{\prime}$ ). The modifications in cell shape and microvilli to static MFs exposure were time-dependent. In fact, lamellar microvilli were observed well before the distortion of the cell shape, which was found at longer time periods of exposure (Figure $5 b^{\prime}, c^{\prime}$ ). Possible modifications of organelles were investigated by TEM. However, even at the longer time periods of exposure to static MFs, the morphology of cytoplasmatic organelles and nucleus was unmodified; in particular, beam shaped nuclei with evident nucleolus and zones of condensed and non-condensed chromatin were detected.

After incubation with CHX for 24 hrs or with PMC for 4 hrs, apoptotic morphologies were detected. Chromatin condensed along the envelope and nucleus fragmented by budding (Figure $4 c, d$ ) or by cleavage (Figure $5 \mathrm{a}$ ). The surface of apoptotic U937 cells become smooth (Figures $4 d, d^{\prime} ; 5 \mathrm{a}, \mathrm{b}$ ). When $U 937$ cells were simultaneously incubated with pro-apoptotic molecules and static MFs for 24 hrs (Figures $4 \mathrm{e}, \mathrm{e}^{\prime} ; 5 \mathrm{~b}, \mathrm{c}$ ), the smoothness of the cell surface, typical of apoptotic cells, was reduced. In fact, attempts at microvilli reformation with a faint lamellar shape were observed.

Modifications of cell surface expression of glycans, as detected by ConA and Ricinus communis-FITC conjugates, were studied by confocal microscopy on control and apoptosis induced U937 cells. ConA and 

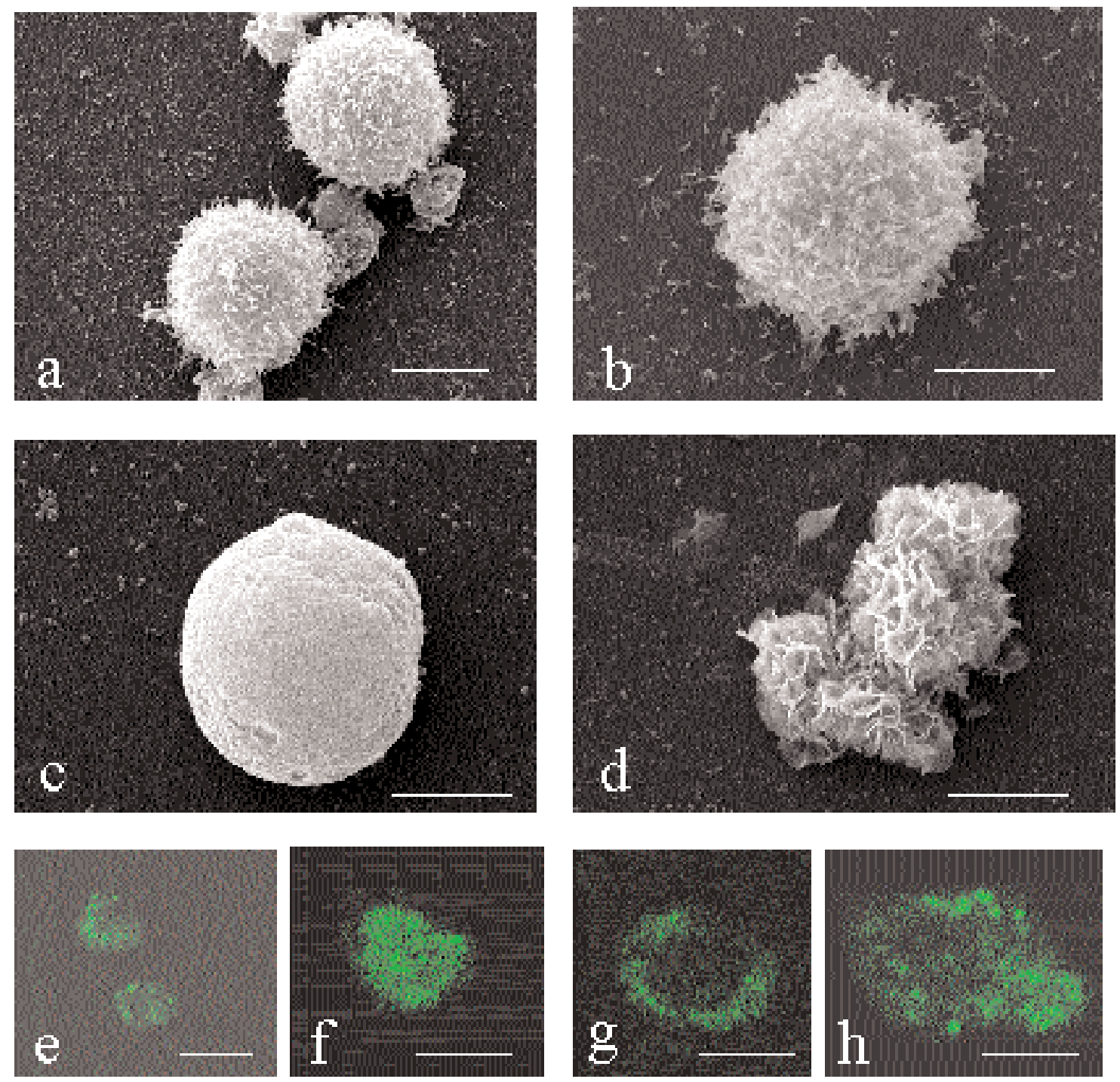

\section{- SMFs 6mT}

\section{+ SMF $6 \mathrm{mT}$}

Figure 3. SEM micrographs (a-d) showing cell shape modifications, and confocal fluorescent micrographs (e-h) showing ConA-FITC labeling to human lymphocytes following the apoptotic treatment in the presence or absence of $6 \mathrm{mT}$ StaticMFs. a) Controls of human lymphocytes are characterized by a round shape with microvilli randomly distributed all over the cell surface. A slight remodeling of the microvilli shape is observed (b) after 18 hrs of exposure to static MFs. c) Round smooth apoptotic lymphocytes without microvilli after treatment with $\mathrm{H}_{2} \mathrm{O}_{2} 100 \mathrm{mM}$ for $1 \mathrm{hr}$. The presence of static MFs during the apoptotgenic treatment dramatically modifies cell shape, which becomes elongated, and microvilli, which appear lamellar (d). Bar $=\mathbf{5} \mu \mathrm{m}$. e) Controls of human lymphocytes. Patches of fluorescence on the entire cell surfaces f). CHX treated human lymphocytes for 24 hrs. Increased binding of ConA-FITC conjugates randomly distributed all over the cell surface. G) $\mathbf{2 4}$ hrs exposure to static MFs of controls of human lymphocytes gives crescent shape distribution of ConA-FITC binding sites, which is lost (h) when cells are contemporaneously exposed to PMC and staticMFs. Bar $=\mathbf{5} \boldsymbol{\mu m}$.

Ricinus communis binding sites, whose amount is not negligible, are randomly distributed on the surfaces of U937 control cells (Figure 6 a, A). Conversely, the apoptotic treatment decreased cell surface mannose and galactose residues of PMCtreated $U 937$ cells (Figure 6 C, C). Fluorescence
(Con-A-FITC) concentrated to one pole of the cell was found. After exposure to static MFs the normal fluorescence distribution observed in control cells was not altered (Figure 6 b, B). However, the exposure to static MFs of PMC-treated U937 cells partially impeded the modifications in the distribution 

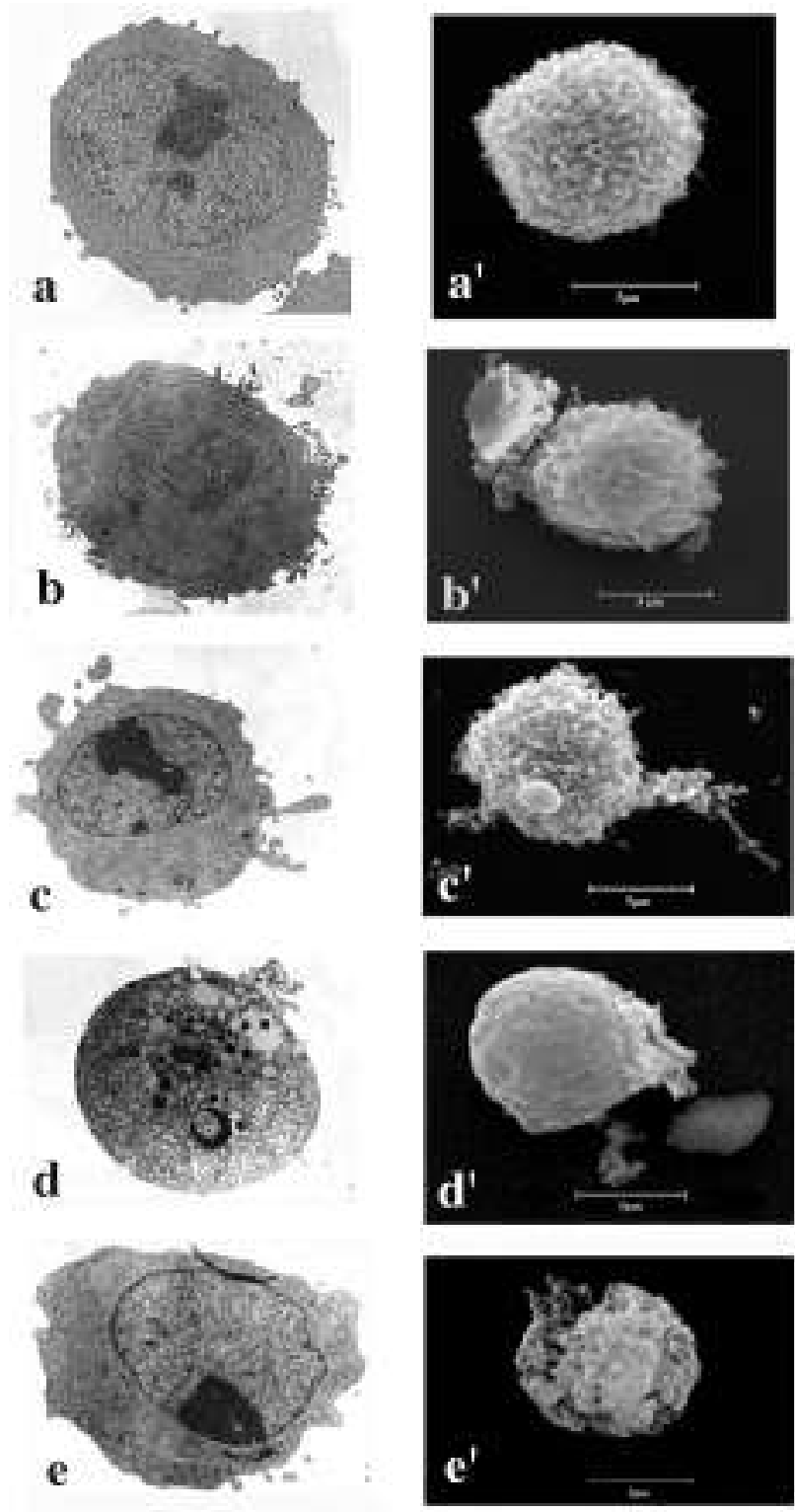

Figure 4. TEM (a,b,c,d,e) and SEM (a',b',c',d',e') micrographs of U937 cells showing cell shape modification following the apoptotic treatment (CHX $10^{-2} \mathrm{M}$ for $24 \mathrm{hrs}$ ) in the presence of $6 \mathrm{mT}$ staticMFs. The $24 \mathrm{hrs}$ continuous exposition to static MFs leads to cell shape distortion and/or lamellar microvilli presence ( $\left.b, b^{\prime}, c^{\prime}, c^{\prime}\right)$ when compared to controls of U937 cells $\left(a, a^{\prime}\right)$. 10-2M CHX for 24 hrs induces apoptosis in U937 cells, showing the characteristic roundness and smoothness of the cell shape (d,d'). Exposure for $\mathbf{2 4}$ hrs to static MFs reduces the apoptotic rate and the smoothness of cell surfaces (e,e'). Bar $=5 \mu \mathrm{m}$.

of cell surface glycans exerted by the apoptogenic inducer (Figure $6 \mathrm{~d}$ ).

One possible cause of the above described modifications could be cytoskeletal alterations, besides the reorientation of molecular domains within the membrane (Rosen 1993). Figure 7 shows the modifica-
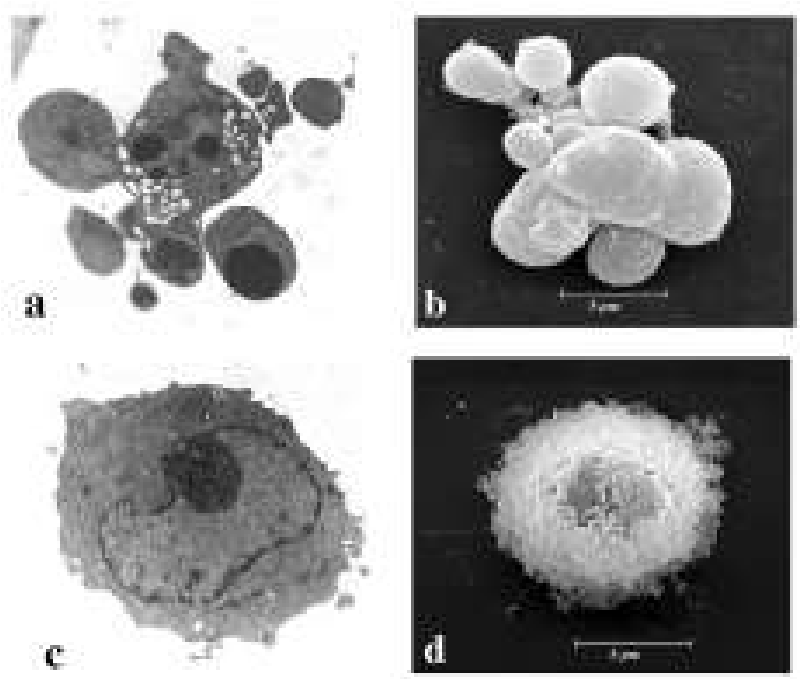

Figure 5. TEM and SEM micrographs of U937 cells showing cell shape modification following PMC treatment $(1 \mu \mathrm{g} / \mathrm{mL}$ for 4 hrs.) in the presence of $6 \mathrm{mT}$ staticMFs. One $\mu \mathrm{g} / \mathrm{mL}$ PMC for 4 hrs induces massive apoptosis and cellular fragmentation $(a, b)$. When $6 \mathrm{mT}$ static MFs and PMC (1 $\mu \mathrm{g} / \mathrm{mL}$ for $4 \mathrm{hrs}$.) are applied simultaneously to U937 cells, a significant reduction of apoptosis and of nuclear and cellular fragmentation together with the onset of lamellar microvilli is observed (c,d). Bar $=5 \mu \mathrm{m}$.

tions in the binding of phalloidin-FITC to U937 cells after exposure to static MFs only and/or after the contemporary treatment of static MFs and PMC. The pro-apoptotic drug induced a remodeling of Factin distribution (Figure $7 \mathrm{~b}$ arrows), further remodeled by the contemporary application of static MFs (Figure 7d).

\section{Discussion}

In this study, we showed that static MFs exert a strong and reproducible effect on the cell shape and on the plasma membrane, as well as on apoptosis in the different cell types; this latter effect is mediated by the MFs ability to increase $\mathrm{Ca}^{2+}$ influx (Fanelli et al. 1999). Other possible effects of static MFs, such as an alteration of the pattern of gene expression, cannot be excluded (manuscript in preparation).

These findings are in agreement with other literature data which indicate that the plasma membrane is a very sensitive target for the action of MFs. MFs of very low intensity can generate cell modifications as was shown by the described experiments with the use of $6 \mathrm{mT}$ magnets. Therefore, in spite of the fact that this is not a high value of magnetic fields, it is nevertheless able to produce changes in the cell structure and function. 


\section{ConA-FITC}
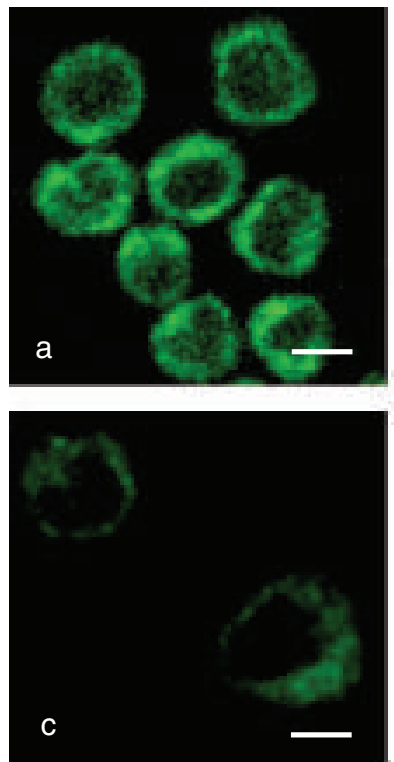

$-\mathrm{SMF} \sigma \mathrm{mT}$
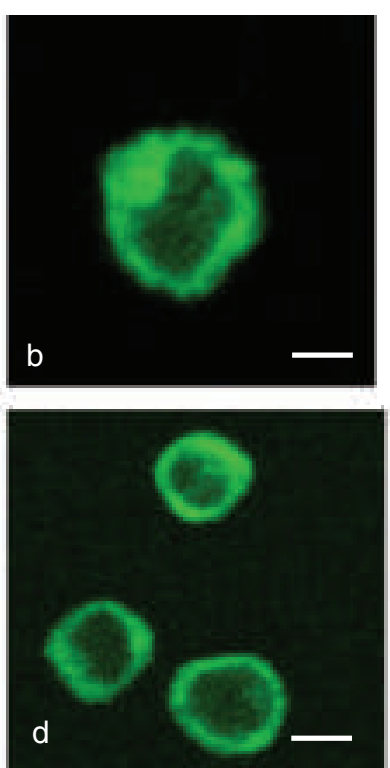

$+\mathrm{SMF}$ s $6 \mathrm{mT}$
Ricinus commois FITC
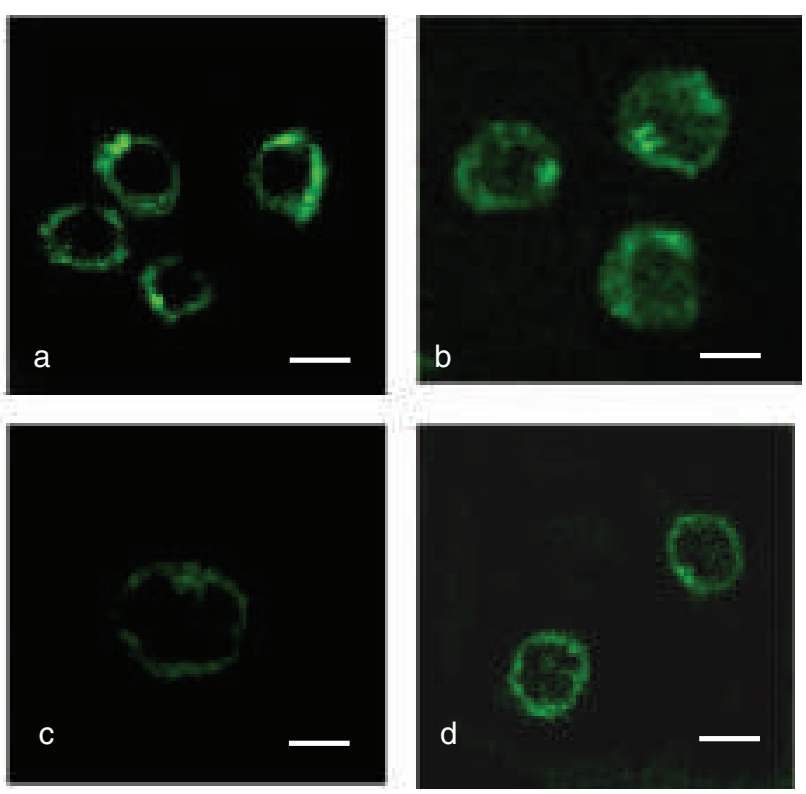

$-\mathrm{SMF} s \mathrm{mT}$

$+\mathrm{SMF} 6 \mathrm{mT}$

Figure 6. Confocal micrographs of ConA (a-d) and Ricinus communis (A-D) binding sites on U937 cells. Lectin FITC conjugates were used. (a, A') Control U937 cells. Surface random distribution of fluorescence. (c, C) Puromycin treated U937 cells for 4 hrs. Loss of ConA and Ricinus communis binding sites parallels the onset of apoptosis. ConA-FITC accumulates preferentially at one pole of the cell. (b, B) $4 \mathrm{hrs}$ of exposure of untreated cells to $6 \mathrm{mT}$ static MFs does not alter the fluorescence distribution or intensity observed for control cells. (d, D) The loss of ConA and Ricinus communis binding sites is impeded when cells are simultaneously exposed to static MFs and PMC. Bar= 5 um.

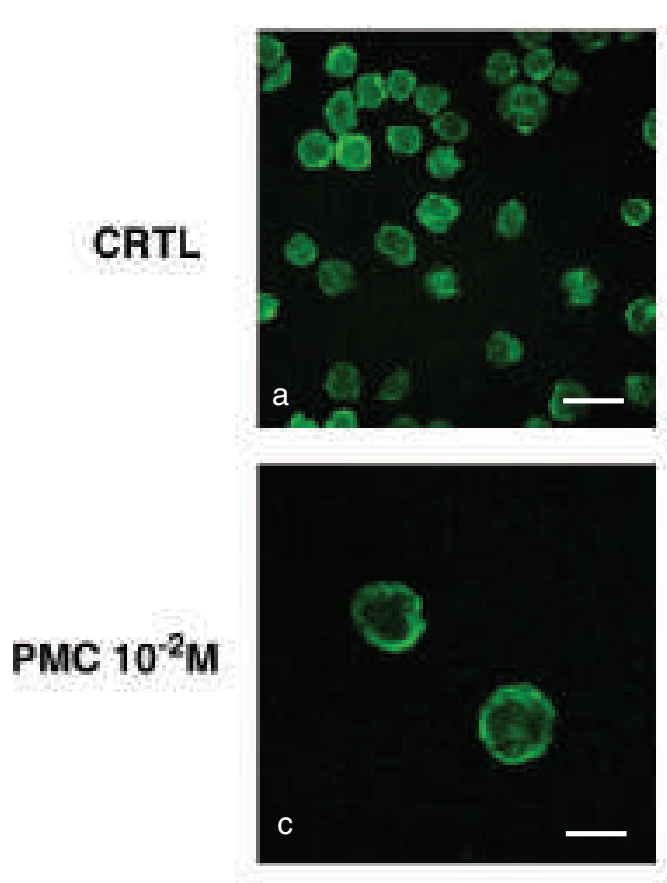

-SMFs
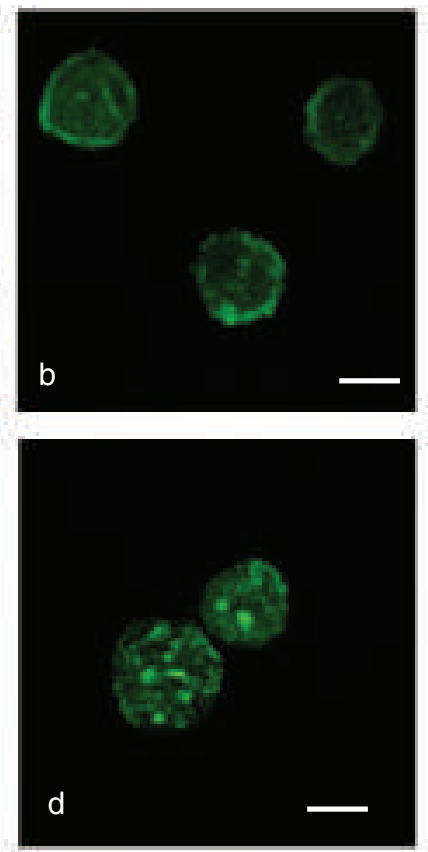

+ SMFs
Figure 7. Confocal micrographs of phalloidin-FITC labeling to U937 cells. a) Random distribution of fluorescence, showing a thick fluorescent ring under the plasma membrane corresponding to the terminal web. b) deaggregation of the thick ring is observed after $4 \mathrm{hrs}$ of exposure of control cells to static MFs (arrow). c) In PMC treated U937 cells, phalloidin-FITC is visible as a thick ring of fluorescence. d) simultaneous exposure to static MFs and PMC destroyed the ring, showing small patches of fluorescence. Bar $=5 \mu \mathrm{m}$. 
The intensity-induced field effects have been investigated elsewhere (Fanelli et al. 1999), while in this paper the time-dependent effects of field exposure have only partially been investigated: i.e. in U937 cells. Our results, in agreement with the data reported by Rosen (1993), in which the duration of the exposure (within certain limits) is important in determining the extent of the plasma membrane as a response to static MFs, show strict differences in the morphology of U937 cells after a short or a longterm exposure to $6 \mathrm{mT}$ static MFs. Moreover, the effects measured are a function of the duration of static MFs exposure up to a limit, above which, longer durations are not associated with further plasma membrane modification. The same results are confirmed when apoptotosis-inducing drugs are given concomitantly with static MFs. Further time course studies are in progress.

When control cells are submitted to static MFs, electron microscopy observations showed alterations in the cell shape and the lamellar microvilli, but without other morphological changes. In fact, the plasma membrane, by virtue of its bioelectrical properties, is the site where EMFs influences are most likely to be exerted (Kell 1986). Uniform field exposure influences the formation of cell protrusions (Patel and Poo, 1982; Onuma and Hui, 1988; Ross et al. 1988). A current of electrons or ions can cause a movement of proteins in the membrane and determine a rearrangement of their position on the membrane surface (Chiabrera et al. 1984). This might be one possible explanation for lectin binding site rearrangements. It could not be excluded that variations in the lipid dynamics described within the $48 \mathrm{hrs}$ from cell seeding in Friends erythroleukemia cell membrane (Volpe et al. 1998), could also favor the movement of ConA and Ricinus communis binding sites.

The changes of cell shape and cell surface micromorphology are closely related to the reorganization of the cytoskeleton elements within the exposed cells (Popov et al. 1991; Santoro et al. 1997). Cytoskeleton reorganization is not due to disruption of its elements, but promotion of their assembly and modulation of their orientation by high magnetic fields in vitro (Bras et al. 1998) might occur. Our preliminary data are more in favor of cytoskeleton re-organization than of cytoskeleton disruption.

One important event during the MFs exposure is the modification in $\mathrm{Ca}^{2+}$ influx. In our experimental model, a two-fold increase in calcium ions has been measured for both cell types. This seems to be a cru- cial event in the cell, since $\mathrm{Ca}^{2+}$ can contribute to many cell functions. For example, some of the available studies suggest that the mechanism of reorganization and breakdown of different cytoskeleton elements is related to modified $\mathrm{Ca}^{2+}$ homeostasis or altered phosphorylation/dephosphorylation state of proteins in exposed cells (Santoro et al. 1997); decreased phagocytic uptake of latex microspheres accompanied by an increased intracellular $\mathrm{Ca}^{2+}$ level in macrophages (Flipo et al. 1998); reduced apoptotic rate (Fanelli et al. 1999).

The decreased rate of apoptosis measured for U937 and lymphocytes is in agreement with other studies which demonstrated that static MFs decrease the rate of apoptosis mainly by interfering with $\mathrm{Ca}^{2+}$ influxes (Fanelli et al. 1999). In fact, variation in the $\mathrm{Ca}^{2+}$ concentration is responsible for entering apoptosis in certain cell types, while others undergo apoptosis by pathways that are independent of the $\mathrm{Ca}^{2+}$ influxes. Static MFs exposure was found to be protective for both lymphocytes and U937 from entering apoptosis. In fact, to confirm this result, for both cell types used, high concentrations of $\mathrm{Ca}^{2+}$ were measured upon concomitant exposure to static MFs and apoptogenic drugs, thus giving further insight into the phenomenon.

It could be hypothesized that some sublethal damage persists in the cells, even when the cell morphology still seems to be normal; in fact, it is known that MFs interfere with DNA repair processes (Chow and Tung, 2000; Robinson et al. 2002) or with altered cell metabolism, thus explaining why MFs act as cotumorigenic or co-carcinogenic factors without by themselves inducing these processes (Looscher and Liburdy, 1998). Alternatively, marked fields alterations of cellular shape and binding sites distribution, may be, in a cascade, responsible for many other perturbations of cell functions such as: decreased phagocytic uptake (Flipo et al. 1998); alteration of receptors (Blumental et al. 1997); drastic alteration of cell morphology leading to the detachment from the culture dish as shown for rat tendon fibroblasts (Blumental et al. 1997); developmental anomalies in chick embryos after exposure to $50 \mathrm{~Hz} E M F$, due to modifications of cell-cell or cellsubstratum interactions (Lahijani and Ghafoori, 2000); cell-mediated immune response alteration in T-cell responses to mitogens (Lahijani and Ghafoori, 2000; Thun-Battersby et al. 1999).

To sum up, the data described in the present paper are in favor for a biological effect of static MFs;. 
even if the perturbations on either U937 cells or lymphocytes by static MFs of $6 \mathrm{mT}$ intensity are sublethal. These perturbations can, especially at longer times of exposure, evolve into progressive accumulation of modifications, i.e. gene expression (personal communication), which, in turn, can act as cotumorigenic or co-carcinogenic factors. Therefore, the importance of understanding deeply the true mode of action of the MFs, as well as that of electromagnetic fields, on living organisms arises from the necessity of protecting human health in the future.

\section{References}

Blank M. Biological effects of environmental electromagnetic fields: molecular mechanisms. Biosystems 1995; 35:175-8.

Blumental NC, Ricci J, Breger L, Zychlinsky A, Solomon H, Chen GG, et al. Effects of low-intensity $A C$ and/or DC electromagnetic fields on cell attachment and induction of apoptosis. Bioelectromagnetics 1997; 18:264-72.

Bonanno E, Tagliafierro G, Carlà EC, Montinari MR, Pagliara P, Mascetti $G$, et al. Synchronized onset of nuclear and cell surface modifications in U937 cells during apoptosis. Eur J Histochem 2002; 46:61-74.

Bras W, Diakun GP, Diaz JF, Maret G, Kramer H, Bordas J, et al. The susceptibility of pure tubulin to high magnetic fields: a magnetic birefringence and X-ray fiber diffraction study. Biophysical J 1998; 74: 1509-21.

Chiabrera A, Grattarola M, Viviani R. Interaction between electromagnetic fields and cells: microelectrophoretic effect on ligands and surface receptors. Bioelectromagnetics 1984; 5:173-91.

Chow K, Tung WL. Magnetic field exposure enhances DNA repair through the induction of DnaK/J synthesis. FEBS Lett 2000; 478: 133-6.

Diaspro A. Confocal and Two-Photon Microscopy: Foundations, Applications and Advances Wiley, 2002.

Fanelli C, Coppola S, Barone R, Colussi C, Gualandi G, Volpe P, et al. Magnetic fields increase cell survival by inhibiting apoptosis via modulation of Ca++ influx. Faseb J 1999; 13:95-102.

Fiorani $M$, Cantoni 0 , Sestili $P$, Conti $R$, Nicolini $P$, Vetrano $F$, et al. Electric and/or magnetic field effects on DNA structure and function in cultured human cells. Mut Res 1992; 282:25-9.

Flipo D, Fournier M, Benquet C, Roux P, Le Boulaire C, Pinsky C, et al. Increased apoptosis, changes in intracellular $\mathrm{Ca} 2+$, and functional alterations in lymphocytes and macrophages after in vitro exposure to static magnetic field. J.Toxicol. Environ Health 1998; 54:63-76.

Goodman, E, Greenebaum, B, and Marron, M. T. Effects of electromagnetic fields on molecules and cells. Int Rev Cytol 1995; 158:279-338.

Grynkiewicz, G, Poenie, M, and Tsien, R.J. A new generation of Ca2+ indicators with greatly improved fluorescence properties. J Biol Chem 1995; 260:3440-50.

Ishisaka R, Kanno T, Inai Y, Nakahara H, Akiyama J, Yoshioka T, et al. Effects of a magnetic fields on the various functions of subcellular organells and cells. Pathophysiology, 2000; 7:149-52.

Kell DB. On the lateral mobility of proteins in prokaryotic membranes. Biochem Soc Trans 1986; 14:825-6.

Khadir R, Morgan JL, Murray JJ. Effects of $60 \mathrm{~Hz}$ magnetic field exposure on polymorphonuclear leukocyte activation. Biochim Biophys Acta 1999; 1472:359-67.

Johnson MT, Vanscoy-Cornett A, Vesper DN, Swez JA, Chamberlain, JK, Seaward MB, et al. Electromagnetic fields used clinically to improve bone healing also impact lymphocyte proliferation in vitro. Biomed Sci Instrum 2001; 37:215-20.

Lahijani MS, Ghafoori M. Teratogenic effects of sinusoidal extremely low frequency electromagnetic fields on morphology of $24 \mathrm{hr}$ chick embryos. Indian J Exp Biol 2000; 38:692-9.

Liburdy RP, Sloma TR, Sokolic R, Yaswen P. ELF magnetic fields, breast cancer, and melatonin: $50 \mathrm{~Hz}$ fields block melatonin's oncostatic action on ER+ breast cancer cell proliferation. J Pineal Res 1993; 14:89-97.

Loberg LI, Engdahl WR, Gauger JR, Mc Cormick DL. Expression of cancer-related genes in human cells exposed to $60 \mathrm{~Hz}$ magnetic fields. Radiat Res 2000; 153:679-84.

Looscher W, Liburdy RP. Animal and cellular studies on carcinogenic effects of low frequency $(50 / 60-\mathrm{Hz})$ magnetic fields. Mutat Res 1998; 410:185-220.

Lyle DB, Fuchs TA, Casamento JP, Davis CC, Swicord ML. Intracellular calcium signaling by Jurkat T-lymphocytes exposed to $60 \mathrm{~Hz}$ magnetic field. Bioelectromagnetics 1997; 18:439-45.

Mc Cann J, Dietrich F, Raffertyy C, Martin A0. A critical review of the genotoxic potential of electric and magnetic fields. Mutat Res 1993; 297:61-95.

Miyakoshi, J, Yamagishi, N, Ohtsu, S, Mohri, K, and Takebe, H. Increase in lipoxanthine-guanine phosphoribosyl transferase gene mutations by exposure to high-density $50 \mathrm{~Hz}$ magnetic fields. Mutat Res 1996; 349:109-14.

Morandi MA, Pak CM, Caren RP, Caren LD. Lack of an EMF-induced genotoxic effect in the Ames assay. Life Sci 1996;59:25-9.

Noredenson I, Mild KH, Anderson G, Sandstrom M. Chromosomal aberrations in human amniotic cells after intermittent exposure to fifty hertz magnetic fields. Bioelectromagnetics 1994;15:293-301.

Onuma EK, Hui SW. Electric field-directed cell shape changes, displacement, and cytoskeletal reorganization are calcium dependent. J Cell Biol 1988; 106:2067-75.

Paradisi S, Donelli G, Santini MS, Straface E, Malori W. A 50 Hz magnetic field induces structural and biophysical changes in membranes. Bioelectromagnetics 1993;14:247-55.

Patel NB, Poo M. Orientation of neurite growth by extracellular electric fields. J Neurosci, 1982;2:483-96.

Popov SV, Svitkina TM, Margolis LB, Tsong TY. Mechanism of cell protusion formation in electrical field: the role of actin. Biochim Biophys Acta 1991;1066:151-8.

Robinson GJ, Pendlenton AR, Monson KO, Murray BK, O'Neill KL. Decreased DNA repair rates and protection from heat induced apoptosis mediated by electromagnetic field exposure. Bioelectromagnetics 2002; 23:106-12.

Rosen AD. Membrane response to static magnetic fields: effect of exposure duration. Biochim Biophys Acta 1993;1148:317-20.

Ross SM. Combined DC and ELF magnetic fields can alter cell proliferation. Bioelectromagnetic 1990; 11:27-36.

Ross SM, Ferrier JM, Aubin JE. Studies on the alignment of fibroblasts in uniform applied electrical fields. Bioelectromagnetics 1988; 10: 371-84.

Santoro N, Lisi A, Pozzi D, Pasquali E, Serafino A, Grimaldi S. Effect of extremely low frequency (ELF) magnetic field exposure on morphological and biophysical properties of human lymphoid cell line (Raji). Biochim Biophys Acta 1997; 1357:281-90.

Thun-Battersby S, Westermann J, Losher W. Lymphocyte subset analyses in blood, spleen and lymph nodes of female Sprague-Dawley rats after short or prolonged exposure to a $50 \mathrm{~Hz}$ 100-micro T magnetic field. Radiat Res 1999; 152:436-43.

Volpe P, Parasassi T, Esposito C, Ravagnan G, Giusti AM, Pasquarelli A, Eremenko T. Cell membrane lipid molecular dynamics in a solenoid versus a magnetically shielded room. Bioelectromagnetics 1998; 19:107-11. 